\title{
Staying Ahead of the Automation: A Vertical Situation Display Can Help
}

\author{
Thomas Prevot \\ San Jose State University/NASA Ames Research Center, Moffett Field, CA
}

Everett Palmer

NASA Ames Research Center, Moffett Field, CA

Copyright (C) 2000 Society of Automotive Engineers, Inc.

\begin{abstract}
In this paper we present a Vertical Situation Display (VSD) for Flight Management System equipped aircraft. It was developed, implemented and evaluated in the Advanced Concepts Flight Simulator at NASA Ames Research Center. The VSD was designed to support flight crews in managing the vertical flight path when using high levels of aircraft automation inside Terminal Areas.
\end{abstract}

\section{INTRODUCTION}

Navigating modern aircraft in the vertical domain can lead to "automation surprises" and altitude busts may occur. Controlled Flight Into Terrain (CFIT) accidents due to a loss of vertical situation awareness are the most serious consequences of unsuccessful vertical flight path management. Research by Wiener (1), Sarter and Woods (2), Palmer et al. (3)(4), Funk et al. (5), Degani (6), Feary et al. (7) and others demonstrates that automation surprises are common events in all automated aircraft types. Most surprises happen in the vertical domain (8)(9). This problem is so serious that some air carriers have disabled the 'vertical navigation' function of Flight Management Systems (FMS) or do not train flight crews on using it (10).

In the long term, such drastic means may result in less cost-effective flights and incompatibilities with future air traffic requirements. Programs aimed at increasing airspace capacity are focused on using ground-based and airborne automation. Tools like the NASA/FAA Center TRACON Automation System (11) are most effective if the aircraft flight paths are highly predictable from take off to touchdown. An essential factor in increasing flight path accuracy and efficiency is the usage of FMS automation during all phases of flight.
Lateral FMS navigation and guidance provides accurate tracking of selected routes. Vertical navigation and guidance takes away a fair amount of the uncertainty of climb and descent profiles.

In light of new developments in Air Traffic Control vertical navigation is shifting towards strategic vertical flight path management. Pilots will have to revert from highly automated to less automated or manual modes and sometimes back to highly automated modes.

We believe that the key for using all levels of automation and shifting between them is a thorough understanding of the behavior of the underlying automation. A flight crew that understands the "what", "why" and "what next" of the automated flight systems is likely to stay ahead of the automation and perform safer and more efficiently in adverse situations. Some of this understanding can be gained through training and experience. However, if the feedback onboard the aircraft is inappropriate, the flight crew may have to hunt for cues that facilitate applying the knowledge. By the time the distributed cues are identified the flight crew may already be behind the automation.

We describe a Vertical Situation Display (VSD) that was developed and evaluated in NASA Ames Advanced Concepts Flight Simulator (ACFS). Similar displays already exist in operation and research (e.g. 9,10,12,13). The VSD that we describe has been developed to support flight management usage during arrival/descent phases of flight. Our ongoing air-ground integration research identifies the need for accurate vertical navigation in a future ATM environment $(14,15,16)$.

In the first part of the paper we explain some of our design decisions. In the second part we present some initial results of a full mission simulation. 


\section{FEEDBACK IN CURRENT AIRCRAFT COCKPITS}

Current aircraft displays provide feedback for lateral path management and vertical flight path control. Lateral flight path management has been enabled through the integration of an electronic map display into modern glass-cockpits. With few exceptions there is no equivalent in the vertical domain (8).

One of the most important accomplishments of the map display in glass-cockpit aircraft is to enable flight crews to assess their lateral position precisely for navigation. Flight crews can easily derive the relative position information necessary to perform and understand lateral flight planning and guidance tasks. This information, depicted on the map display with its MAP mode for local areas and its PLAN mode for extended areas, allows pilots to program flight plans into the flight management system and graphically evaluate the resulting lateral flight path. When the lateral guidance of the aircraft is delegated to the FMS, flight crews can monitor the state of the aircraft relative to the lateral flight path and anticipate the future behavior. Control commands can be monitored using the Flight Mode Annunciation (FMA), the heading indicator, and the Attitude Direction Indicator (ADI), where the bank angle represents the direct feedback of the roll steering commands the control function generates. The crew can monitor all management tasks (navigation, flight planning, guidance and control) in the horizontal domain. This kind of appropriate feedback has resulted in very good lateral route tracking performance in modern glass-cockpit aircraft.

In the vertical domain the displays only depict information supporting the control task (14,15). The FMA annunciates the speed and pitch control modes. The altitude, vertical speeds and pitch can be derived from the ADI. Profile management information has to be gathered from different CDU pages. Figure 1 shows an example from a full mission simulation conducted in summer 2000 replayed using the Crew Activity Tracking System CATS (16). The two crewmembers select the DEScent page and the LEGS page to get alphanumeric information on path adherence and upcoming altitude and speed constraints and restrictions. Current information on altitude and vertical speed is depicted on the ADI

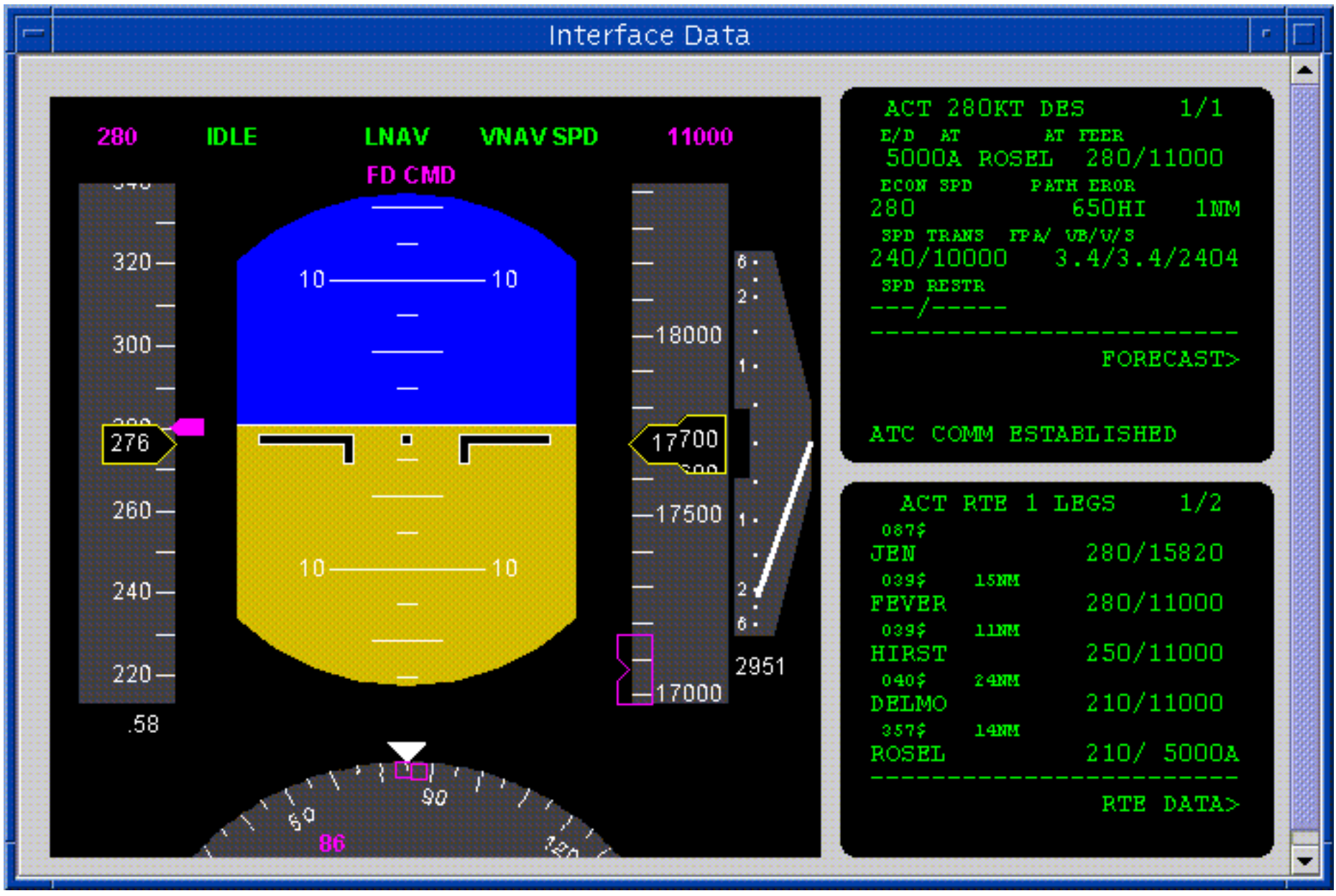

Figure 1: Example for distributed vertical profile information in current glass cockpits 
Feary et al. (7) developed a guidance FMA, that annunciates the operational procedures used to develop the guidance behavior of the MD 11 aircraft. This FMA was evaluated during training sessions in order to determine whether it helps pilots understanding the vertical navigation of the aircraft. This guidance FMA resulted in better performance, but it does not completely resolve the problem.

A guidance FMA helps pilots within the limitations of current cockpits with the aircraft guidance, but does not provide additional feedback for the navigation (and flight planning). The relative position of the aircraft in the vertical domain still has to be inferred from a variety of sources. The absolute position is displayed on the altitude tape while the reference positions of the flight path are depicted in an alphanumeric format on the CDU LEGS page or on the map display attached to the flight plan waypoints when selected by the pilot. Since easing position assessment for flight crews was one of the main accomplishments in the lateral domain, this can also be the key for appropriate feedback for vertical flight path management. This holds true also for other outcomes of the navigation task, like the airspeed and the vertical speed.

One reason for the feedback discrepancy between lateral and vertical flight path management is that the displays have not kept up with FMS evolution. Older and less sophisticated flight management systems provide only automation for lateral path management and require that the pilots perform most of the tasks in the vertical domain in less automated modes. Additionally, vertical flight path management is only important in climb and descend phases of flight (and the transitions between different flight phases). In today's ATC systems, these phases are mainly subject to tactical flight level changes instructed by air traffic controllers. There are several developments that will require increasing use of vertical flight path (including speed) management in the near future.

\section{DISPLAY DESIGN}

Our goal was to design a display that provides feedback for the vertical flight management tasks of navigation, flight planning and guidance. Flight path management is at least a three-dimensional task, so the question of the display dimensionally has to be raised. One common result of research on display dimensionally is that the appropriate format is task dependent.

\section{DISPLAY DIMENSIONALLY}

We decided to use a co-planar view consisting of MAP display and VSD based on the following thoughts:

- First, feedback for flight path management is aimed at global situation awareness. Aircraft control feedback (e.g. pitch and thrust modes) will still be provided through the information on the ADI and the FMA. Information for global situation awareness is better represented in a co-planar view, control feedback in a perspective view.

- Secondly, one of the main goals of the VSD is to display the vertical position information unambiguously. 3D scenes are always ambiguous as to the true position of any point in space.

- Thirdly, the flight management system manages the lateral and the vertical flight path mainly independently. A co-planar view provides the same kind of feedback.

- Finally, vertical flight path management is only important in certain phases of flight. During other long portions (like the cruise flight) the profile view may not be necessary and can be turned off. The available region for the map display can increase, without changing the main internal display geometry. Thus, the operator does not have to accommodate a new display in his mental representation.

By choosing the co-planar view one should be aware of the mental geometry necessary for pilots to integrate the information on the VSD and the ND. But as neither map display nor VSD is intended to provide control feedback, we consider this shortcoming less problematic.

\section{COLOR-CODING}

The VSD color-coding reflects the color-schemes used in the particular aircraft. Therefore, for an operational implementation the color schemes have to be adapted to the MAP display. The currently implemented prototype uses the following underlying scheme:

\section{- magenta:}

active targets (active FMS flight plan, active waypoint, commanded speed, commanded MCP altitude, if the vertical flight path is not managed by the FMS)

- white:

pre-selected values (modified FMS flight plan, altitude and speed constraints, if the FMS is managing the vertical flight path)

- white (on gray background):

aircraft state information for current altitude and speed,

\section{- green:}

extrapolation of the current flight path (projection of the green arc on the Map display)

- amber:

altitude and speed constraints, if the vertical flight path is not managed by the FMS in order to draw the pilot's attention to upcoming constraints. 


\section{INTEGRATING THE VSD WITH THE MAP DISPLAY}

The VSD is integrated into the cockpit infrastructure to complement existing displays. The constraints on modern flight decks including available display size, color coding and data accessibility have been taken into account such that it could be part of next generation flight decks as well as retrofitted into current generation transport aircraft.

The VSD may not be needed during all phases of flight. It can be turned on at the navigation display control panel in addition to the MAP display in a co-planar and a full view. The display has been implemented in the part-task and the full mission version of NASA Ames Advanced Concepts Flight Simulator. Figures 2 and 3 represent two possible pilot selections:

The waypoint and wind information in the upper left and right corners of the display remains unchanged. The range of the VSD is slaved to the range of the map display and similar color conventions are used.

In cases, where pilots want to focus only on the lateral domain, the VSD can be turned off and the graphical map display remains unchanged.

In figure 2 the map display has been re-scaled to $60 \%$ of its original size and translated above the VSD. Flight crews may select this view if they want to have a comprehensive picture of their situation

In figure3 the VSD becomes the dominant display. This selection allows pilots to assess the vertical situation without being distracted by additional display clutter using almost all available display space.

\section{CHARACTERISTICS OF THE VSD}

The particular VSD characteristics will be described using the flight situations depicted in figure 2 and figure 3 . In this example the display is scaled to a range of 40 nautical miles. The altitude range is scaled such that most

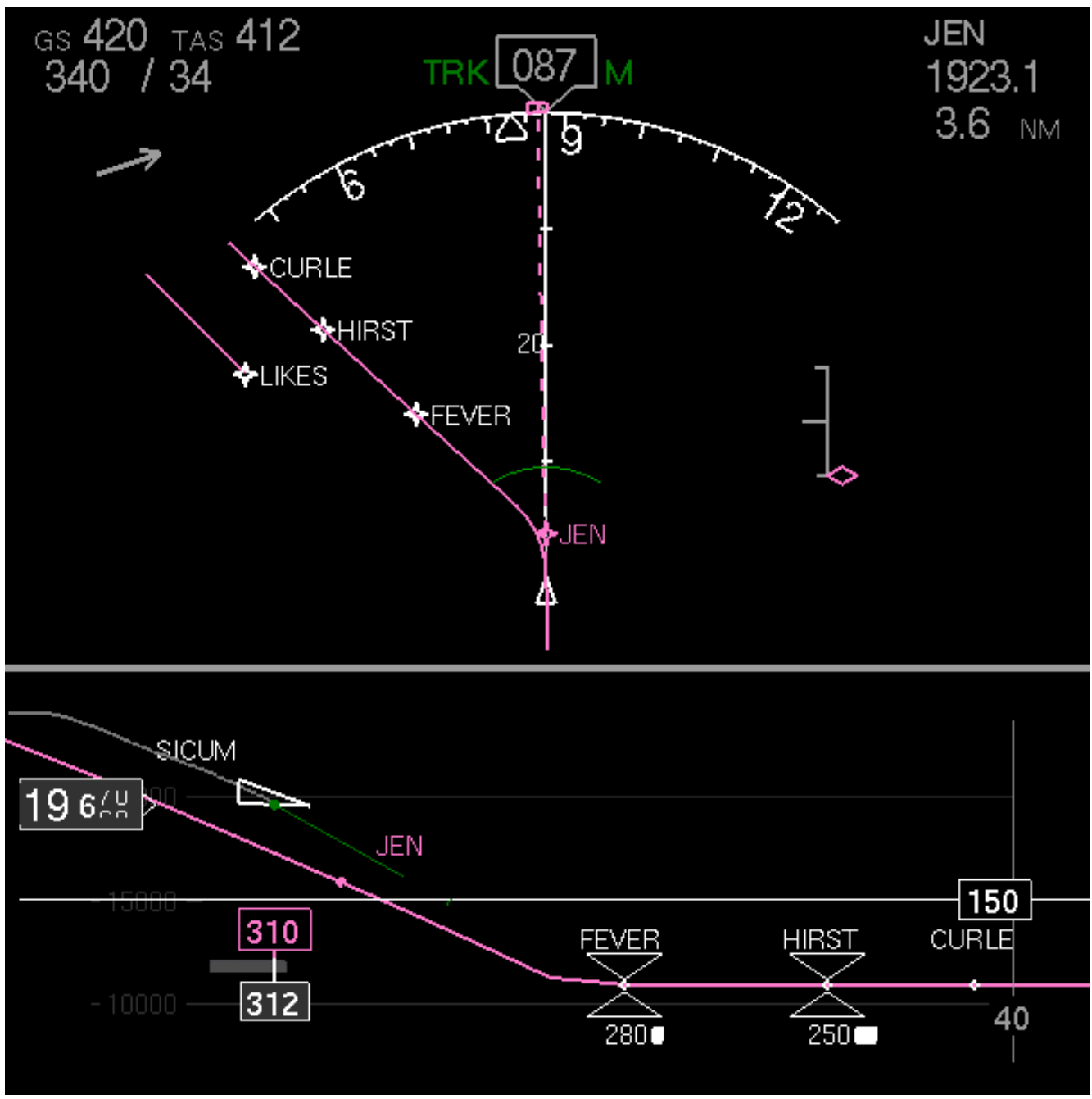

Figure 2: Co-planar view of map display and vertical situation display 
of the future flight path is visible. Up to a selected display range of $80 \mathrm{NM}$ the range/altitude ratio remains constant to allow pilots to create a mental picture of a steep vs. a shallow path. The altitude range in feet is determined as the selected display range (NM) times 500. (E.g. a selected display range of $40 \mathrm{NM}$ leads to an altitude range of 20.000 feet). The aircraft symbol (white triangle) is at a constant position at the lower half during climb and at the upper half during descent, like in this case. When the aircraft approaches the ground (or the cruise altitude), the aircraft symbol moves down (or up) and the and velocity in the vertical domain in relation to meaningful and important objects. The aircraft symbol is indicated as a triangle, rotating according to the current pitch angle around the reference point depicted as a green dot. The green line starting from this dot represents the current flight path angle. The aircraft altitude is displayed on the left side. The example below shows that the aircraft (white triangle) is high on the descent path at 19420 feet. The current altitude target is 15000 feet, which is indicated by the number (150) in the box on the right side and a line across the display.

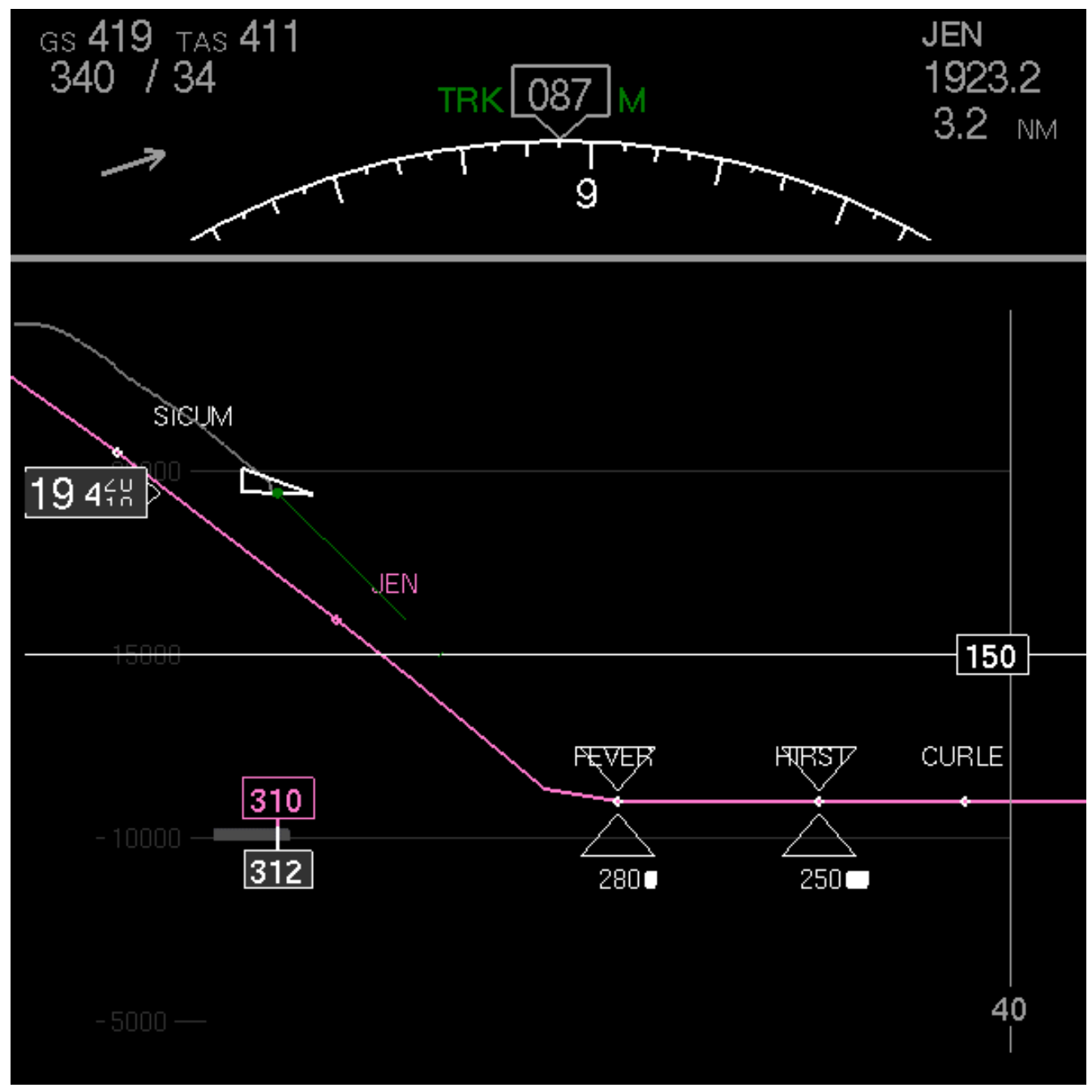

Figure 3: Vertical Situation Display in "full" mode

altitude scale remains constant. Thus, the closure to the ground (cruise altitude) becomes visible.

The display supports vertical navigation, flight planning and guidance as follows:

\section{NAVIGATION}

To support the flight crews' understanding of the navigation task, the display indicates the aircraft position
The line is solid, if the MCP altitude constrains the descent, and dashed if not. The airspeed is indicated in relation to the commanded (magenta) or pre-selected (white) speed underneath the aircraft symbol. When both differ significantly the gap between current and target speed becomes visible. The shaded area between them indicates the current speed envelope limitations 
The display supports vertical flight planning tasks by depicting the current state of the active flight plan and any modification to it that will be used for managing the aircraft in an along track picture. Therefore, all points along the flight plan are displayed at which new commands will be issued to the guidance. The display indicates constraints along the flight path and enables flight crews to determine whether the generated flight plan will meet the constraints. Altitude constraints are indicated as triangles, speed constraints in alphanumeric format below. A modified flight plan is indicated as a white line overlaying the magenta line of the active flight plan

\section{GUIDANCE}

The display shows the current target values for altitude and speed and clearly indicates whether the FMS manages the vertical flight path or the flight crew must guide the aircraft along the path. This is achieved by using a solid flight path line if the FMS manages the vertical flight path, and a dashed flight path line if not. The green line extrapolates the aircraft velocity vector for one minute. The relation of the green predictor line to the magenta flight path allows pilots to assess whether the aircraft is trying to get back to the path. The relation of the current airspeed to the commanded airspeed indicates whether the speed is held. This combination allows flight crews to anticipate the future behavior of the aircraft and make the necessary adjustments to comply with constraints in the vertical domain.

\section{FULL MISSION SIMULATION STUDY}

In fall 1998 a full mission simulation was conducted at NASA Ames' Advanced Concepts Flight Simulator (ACFS) to investigate flight crew factors for Flight Management System (FMS) usage in the extended terminal airspace. The ACFS is a full-mission simulator with a "generic" glass cockpit layout based on current generation Boeing-type displays. The simulation model represents a Boeing 757 . Twelve airline flight crews participated in the study and flew seven descents from cruise altitude to touchdown in the Dallas Fort Worth airspace. Three different interface conditions were investigated. The crews were required to fly at different levels of automation ranging from current day procedures requiring step-by-step entry of target values for altitude, speed and heading into the autopilot, to fully automated modes coupled to the FMS until final approach. The main purpose of the study was to investigate crew interfaces that enhance the compatibility between ground automation and flight deck automation.

The VSD was an independent variable in this study made available to half of the crews. Crews provided with the VSD were free to select the co-planar or the full mode at any time. They were asked to turn it off in the final phase

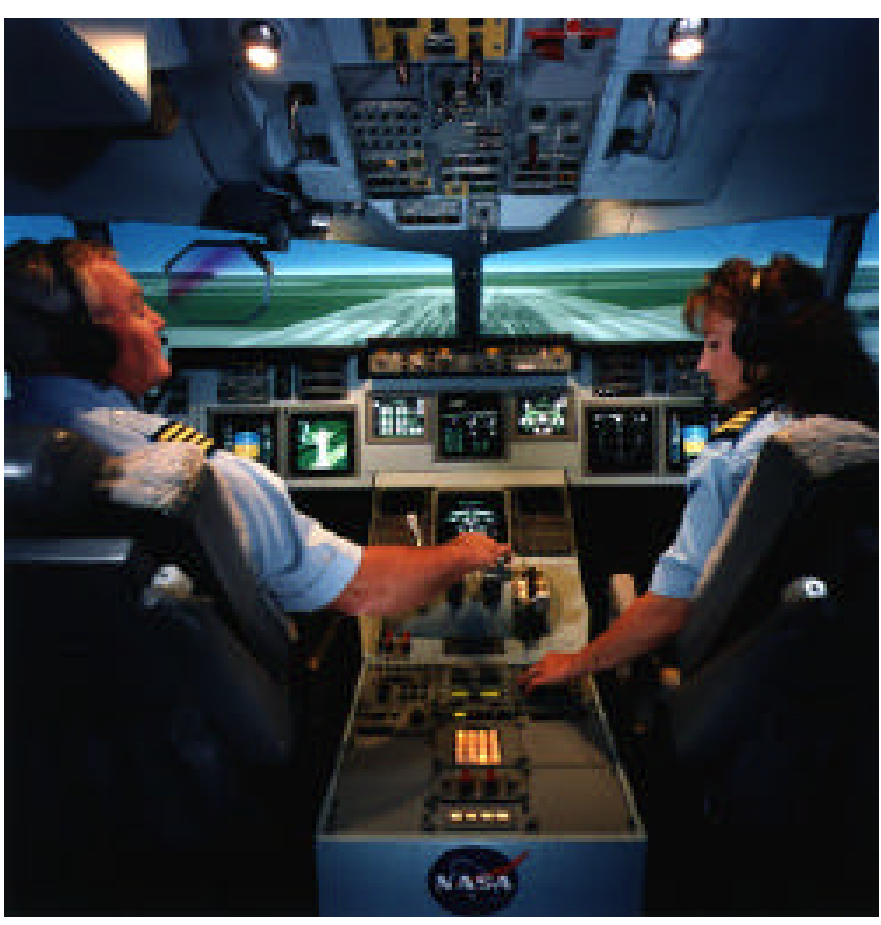

Figure 4: Advanced Concepts Flight Simulator (ACFS) at NASA Ames Research Center

of flight, because the VSD was not designed for controlling the aircraft during approach.

The following paragraphs present an overview of some general results and discuss the particular results of the subjective assessment of the VSD by the flight crews and how they were using it. For details on other aspects see Crane et al. (1999).

\section{GENERAL RESULTS}

The flight crews considered the scenarios flown realistic for moderate traffic situations, but not very challenging. Overall flight crew performance was at a very high level for all interface conditions and runs. The VSD did not affect this overall high crew performance. The workload assessment using the NASA TLX methodology showed no significant differences between the crews having the VSD available, and those who did not.

We believe that in order to expect differences in workload or crew performance caused by the VSD more challenging scenarios are required including higher traffic density and worse weather environments. Some of these conditions are part of a full mission simulation conducted in summer 2000. 


\section{SUBJECTIVE ASSESSMENT BY THE FLIGHT CREWS}

The six flight crews that had the VSD available were asked to state their opinion and experience with the VSD in a questionnaire at the end of the experiment. 11 Results from 6 first officers and 5 captains were received. Figure 5 summarizes the main questions.

Subjectively almost all crewmembers felt more ahead of
The subjects were also asked which display features they found most helpful. The following features were named most frequently:

1. Magenta vertical flight path depiction: $\quad 9$

2. Altitude/speed crossing restrictions: 8

3. 1 minute green flight path angle predictor line: 7

4. Altitude display, speed display, speed bug value, color coding for managed and unmanaged crossing restrictions:

\begin{tabular}{|c|c|c|c|c|c|}
\hline Question & \multicolumn{5}{|c|}{ Answer-option } \\
\hline $\begin{array}{l}\text { Did you feel more "ahead" or } \\
\text { less "ahead" of the airplane } \\
\text { with the VSD? }\end{array}$ & $\begin{array}{c}\text { Much less } \\
0\end{array}$ & $\begin{array}{c}\text { Somewhat } \\
\text { less } \\
\mathbf{1}\end{array}$ & $\begin{array}{c}\text { Border } \\
\text { line } \\
0\end{array}$ & $\begin{array}{l}\text { Somewhat } \\
\text { more } \\
\mathbf{5}\end{array}$ & $\begin{array}{l}\text { Much } \\
\text { more } \\
\mathbf{5}\end{array}$ \\
\hline $\begin{array}{l}\text { Did use of the VSD distract } \\
\text { you from performing other } \\
\text { cockpit tasks? }\end{array}$ & \multicolumn{3}{|c|}{ Yes } & \multicolumn{2}{|c|}{11} \\
\hline $\begin{array}{l}\text { Did use of the VSD distract } \\
\text { you from monitoring other } \\
\text { cockpit displays? }\end{array}$ & \multicolumn{2}{|r|}{ Yes } & \multicolumn{3}{|c|}{ No } \\
\hline $\begin{array}{l}\text { In general, how helpful or } \\
\text { unhelpful was the VSD in } \\
\text { aiding your management of the } \\
\text { descent? }\end{array}$ & $\begin{array}{c}\text { Very } \\
\text { unhelpful } \\
0\end{array}$ & $\begin{array}{c}\text { Somewhat } \\
\text { unhelpful } \\
0\end{array}$ & $\begin{array}{c}\text { Border } \\
\text { line } \\
0\end{array}$ & $\begin{array}{l}\text { Somewhat } \\
\text { helpful } \\
4\end{array}$ & \begin{tabular}{|c} 
Very \\
helpful \\
7
\end{tabular} \\
\hline $\begin{array}{l}\text { Did having the VSD increase } \\
\text { or decrease your monitoring } \\
\text { demands? }\end{array}$ & $\begin{array}{c}\text { Greatly } \\
\text { decreased } \\
0\end{array}$ & $\begin{array}{l}\text { Somewhat } \\
\text { decreased } \\
\mathbf{2}\end{array}$ & $\begin{array}{l}\text { Unaf- } \\
\text { fected } \\
\mathbf{3}\end{array}$ & $\begin{array}{l}\text { Somewhat } \\
\text { increased } \\
\quad \mathbf{6}\end{array}$ & $\begin{array}{c}\text { Greatly } \\
\text { increased } \\
\mathbf{1}\end{array}$ \\
\hline $\begin{array}{l}\text { Did having the VSD increase } \\
\text { or decrease your overall } \\
\text { workload? }\end{array}$ & $\begin{array}{l}\text { Greatly } \\
\text { decreased } \\
1\end{array}$ & $\begin{array}{l}\text { Somewhat } \\
\text { decreased } \\
\mathbf{5}\end{array}$ & $\begin{array}{l}\text { Unaf- } \\
\text { fected } \\
\mathbf{3}\end{array}$ & $\begin{array}{l}\text { Somewhat } \\
\text { increased } \\
\quad \mathbf{2}\end{array}$ & $\begin{array}{c}\text { Greatly } \\
\text { increased } \\
\mathbf{0}\end{array}$ \\
\hline $\begin{array}{l}\text { Did the VSD help you to } \\
\text { understand how the FMS } \\
\text { manages the flight path? }\end{array}$ & \multicolumn{3}{|c|}{$\begin{array}{c}\text { Yes } \\
7\end{array}$} & \multicolumn{2}{|c|}{$\begin{array}{l}\text { No } \\
\mathbf{4}\end{array}$} \\
\hline
\end{tabular}

Figure 5: Summary of questionnaire

the airplane having the VSD available. The one pilot that answered "somewhat less" to question number 1 gave highest marks for the VSD on all other questions. The VSD was said to be helpful and not distracting.

Seven out of eleven crewmembers claimed that the VSD helped them understand how the FMS manages the flight path. Some crews mentioned that this could also be a very useful training tool.
Comments on the flight path depiction include that it's "easy to interpret", a "planview of descent" and "same as magenta LNAV path, it's where we want to be". The crossing restrictions were said to be a "good memory aid", "allowed advanced planning to stay ahead", "Not too useful", "Very useful", "easy to read" and "too small". 


\section{USAGE OF THE VERTICAL SITUATION DISPLAY}

The crews were trained on how to interpret the VSD in a 15 minute briefing using display snapshots in which the symbology was explained. They were briefed on how to select and deselect the two available modes, co-planar and full VSD, and told to deselect the VSD during final approach. Figure 6 shows the time the VSD was used in relation to the flight time from cruise altitude to 5000 feet for 40 runs performed by 6 different flight crews.

Usage of the VSD was not consistent across pilots, as

\section{CONCLUDING REMARKS}

Vertical flight path management is currently one of the most problematic areas in glass cockpit aircraft. Air traffic is progressing towards increased usage of flight management automation in terminal areas. Flight crews need to stay ahead of the complex vertical navigation functions. We designed and initially evaluated a Vertical Situation Display that can help with gaining a better understanding of the aircraft automation.

The very positive crew feedback and frequent usage of the VSD demonstrate that design and integration of the

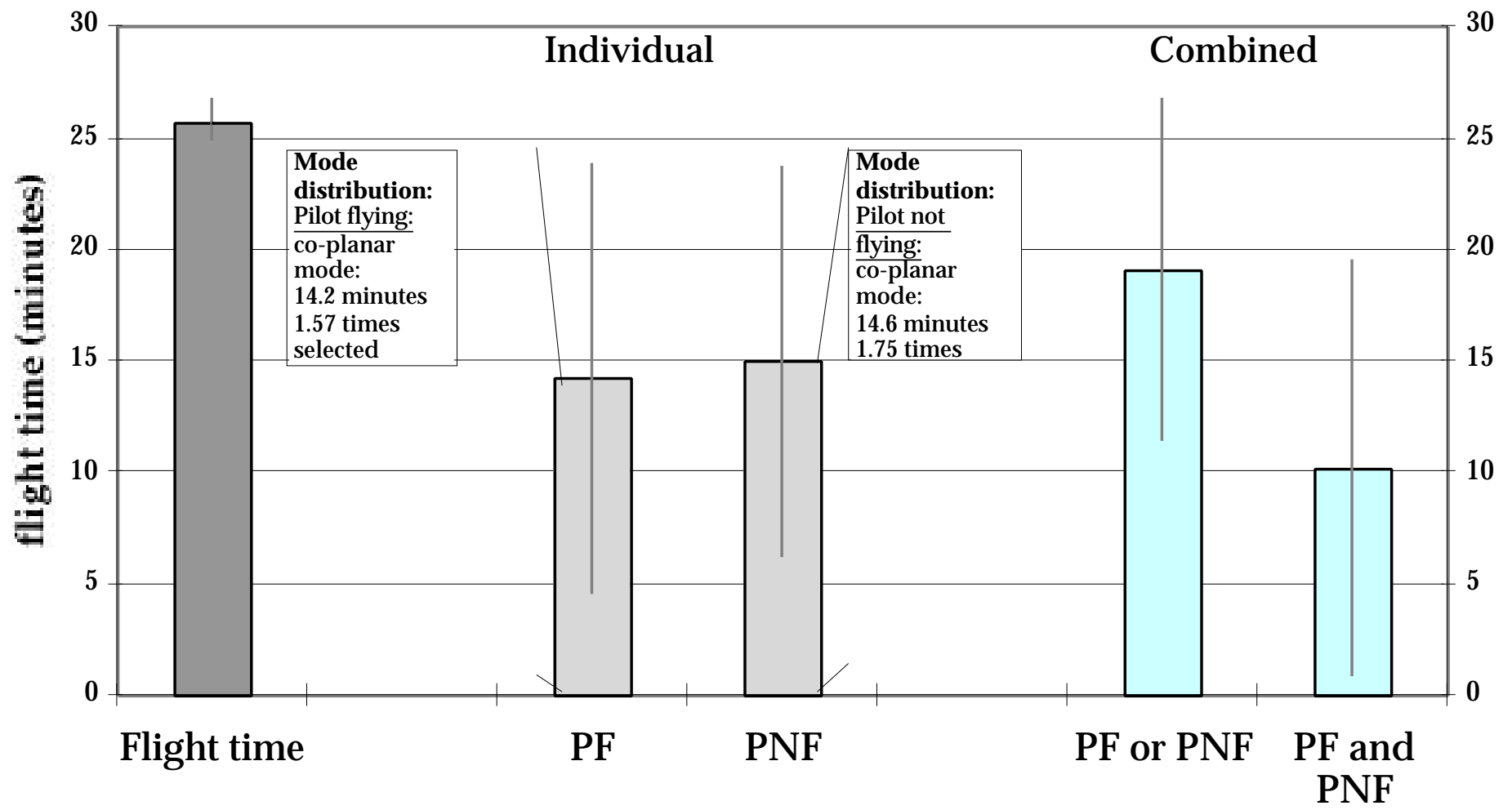

Figure 6: VSD usage in relation to flight time from cruise to 5000 feet. Mean and standard deviation. Sample size: 40 runs with 6 flight crews, each at least 5 runs with alternating positions

the large standard deviations indicate. One captain hardly ever used it, whereas many crewmembers used the VSD during the entire descent. On average either the Pilot Flying (PF) or the Pilot Not Flying (PNF) had the VSD selected during $75 \%$ of the flight time. Both crewmembers used the VSD simultaneously for $30 \%$ of the time. The shared co-planar mode was clearly preferred and used almost all the time (>98\%) the VSD was selected. The full mode was rarely used and only for a few seconds. VSD usage between the PF and the PNF was similar.
VSD are appropriate for current glass cockpits. The pilots reported that the VSD allowed them to stay ahead of the airplane, provided a better understanding of what the automation was doing and that the VSD did not distract them from their other duties.

\section{ACKNOWLEDGMENT}

Barry Crane primarily conducted the full mission study in 1998. Todd Callantine conducted the (ACFS) airborne side of the full mission study in summer 2000 . 
This research was supported by the Terminal Area Productivity (TAP) element of the Aviation System Capacity Program.

\section{REFERENCES}

1. Wiener, E.L (1989). Human factors of advanced technology ("glass-cockpit") transport aircraft. NASA Contractor Report No. 177528. NASA Ames Research Center, Moffett Field, CA

2. Sarter, N. B. and Woods, D. D. (1993) Cognitive Engineering in Aerospace Application: Pilot Interaction with Cockpit Automation. NASA Contractor Report 17761

3. Palmer, E. A., Hutchins, E., Ritter, R. and van Cleemput, I. (1993). Altitude Deviations: Breakdowns of an Error Tolerant System (NASA TM 108788). Moffett Field, CA

4. Palmer, E. A. (1995). "Oops, it didn't arm." A case study of two automation surprises. Proceedings of the Eighth International Aviation Psychology Symposium, Ohio State University, Columbus, $\mathrm{OH}$.

5. Funk, K., Lyall, B. and Riley, V. (1995) A comprehensive analysis of flightdecks with varying levels of automation (Phase 1 Final Report-Perceived human factors problems of flightdeck automation). Eugene OR: Oregon State University

6. Degani, A. (1996) Modeling Human-Machine Systems: On Modes, Error and Patterns of Interaction. Dissertation. Georgia Tech

7. Feary, M., McCrobie, D., Alkin, M., Sherry, L., Polson, P., Palmer, E. and McQuinn, $\mathrm{N}$ Aiding Vertical Navigation Understanding, Final Report NASA Ames Research Center.

8. AW\&ST (1995) Aviation Week and Space Technology (1995) Automated Cockpits Special Report I\& II. Mcgraw Hill Publication, January 30, 1995, February 61995.

9. Vakil, S. S., Midkiff, A. H. and Hansmann, R. J. (1996) Development and Evaluation of an Electronic Vertical Situation Display. NASA GRANT NAG1-1581

10. Hutchins, E. (1996) The Integrated Mode Management Interface Final Report. NASA Ames Research Center, Moffett Field, CA
11. Erzberger, H. (1994) Concerning the Center-TRACON Automation System (CTAS) Presented to the FAA R \& D Advisory Committee, July 12, 1994, Washington, DC

12. Fadden, D. M., Braune, R. and Wiedemann, J. (1993) Spatial displays as a means to increase pilot situational awareness in Pictorial Communication in Virtual and Real Environments (Ellis, Kaiser and Grunwald Edts.) Taylor and Francis, London

13. van Grent, R. N. H. W. (1997) Free Flight with Airborne Separation Assurance. Proceedings of the 10th European Conference, Free Flight, Amsterdam

14. Palmer, E.A. Williams, D.H. Prevot, T. Romahn,S. Goka, T. Smith, N. and Crane,B (1999) An Operational Concept for Flying FMS Trajectories in Center and TRACON Airspace in Proceedings of the 10th Int. Symposium on Aviation Psychology May 3-6,1999, Columbus, $\mathrm{OH}$.

15. Prevot, T., Crane, B., Palmer, E.A., and Smith, N. (2000) Efficient Arrival Management Utilizing ATC and Aircraft Automation, HCI-Aero 2000, Toulouse

16. Prevot, T., Palmer, E. A. and Crane, B. (1997) Flight Crew Support for Automated Negotiation of Descent and Arrival Clearances. Proceedings of the NinthInternational Aviation Psychology Symposium, Ohio State University, Columbus, $\mathrm{OH}$.

17. Prevot, T. (1998) A Display for Managing the Vertical Flight Path- an Appropriate Task with Inappropriate Feedback Proc. HCI Aero'98, Montreal, Canada

18. Sherry, L. and Polson, P. A New Direction for Automation Research: Shared Models of the Avionics.

19. Callantine, T. J. (2000) A Glass Cockpit Crew Activitiy Analysis Tool, SAE 2000-01-5522

\section{CONTACT}

Dr. Thomas Prevot is investigating the integration of new ATC and aircraft automation in the extended Terminal Area. He also developed the Vertical Situation Display under the Terminal Area Productivity Program (TAP). He can be contacted at tprevot@mail.arc.nasa.gov.

Dr Everett Palmer is leading several human-automation research activities and is the manager of the TAP Air Traffic Management project. He can be contacted at epalmer@mail.arc.nasa.gov. 